\title{
In Vitro Antioxidant, Cytotoxic Activities, and Phenolic Profile of Senecio glaucus from Saudi Arabia
}

\author{
Ali S. Alqahtani, ${ }^{1,2}$ Rashed N. Herqash, ${ }^{2}$ Omar M. Noman, ${ }^{2}$ Fahd A. Nasr $\left(\mathbb{D},{ }^{2}\right.$ Nouf Alyhya, ${ }^{3}$ \\ Shamsa H. Anazi, ${ }^{3}$ Muhammad Farooq, ${ }^{3}$ and Riaz Ullah $\mathbb{D}^{2}$ \\ ${ }^{1}$ Department of Pharmacognosy, College of Pharmacy, King Saud University, P.O. Box 2457, Riyadh 11451, Saudi Arabia \\ ${ }^{2}$ Medicinal, Aromatic and Poisonous Plants Research Center, College of Pharmacy, King Saud University, Riyadh 11451, \\ Saudi Arabia \\ ${ }^{3}$ Department of Zoology, College of Science, King Saud University, P.O. Box 2455, Riyadh 11451, Saudi Arabia
}

Correspondence should be addressed to Riaz Ullah; rullah@ksu.edu.sa

Received 31 August 2020; Revised 6 October 2020; Accepted 15 October 2020; Published 24 October 2020

Academic Editor: Fatima Martel

Copyright (c) 2020 Ali S. Alqahtani et al. This is an open access article distributed under the Creative Commons Attribution License, which permits unrestricted use, distribution, and reproduction in any medium, provided the original work is properly cited.

\begin{abstract}
Current treatments for complex diseases have remarkable side effects that negatively impact patients' quality of life. Thus, natural compounds with fewer side effects represent a promising source for safe drugs. The genus Senecio is widely used in folk medicine due to its various pharmacological properties. In the present study, the total phenolic content of Senecio glaucus, which is grown in Saudi Arabia, was assessed using the Folin-Ciocalteau colorimetric method. Scavenging DPPH and ABTS assays were utilized to determine the antioxidant properties of S. glaucus fractions, and MTT assay was used to screen the cytotoxic activity of S. glaucus against various cancer cells. In addition, HPLC-UV was utilized to detect the presence of two phenolic acids, namely, vanillic acid (VA) and gallic acid (GA). Among all fractions tested, S. glaucus chloroform fraction (SGCF) yielded the highest value $(125.3 \mathrm{mg} \cdot \mathrm{GA} / \mathrm{g})$ in terms of total phenolic content. SGCF also exhibited the highest scavenging activities (76.7 and $74.1 \%)$ on both DPPH and ABTS assays, respectively. Similarly, SGCF also possessed the most potent cytotoxic activity against the MCF-7 cell line, with an $\mathrm{IC}_{50}$ value of $41.8 \mu \mathrm{g} / \mathrm{ml}$. The validated HPLC method confirmed the presence of VA $(4.8 \mu \mathrm{g} / \mathrm{mg}$ DW) and GA (3.9 $\mu \mathrm{g} /$ mg DW) in SGCF. Overall, our data show that S. glaucus had antioxidant and cytotoxic properties. A developed validated HPLC method which could be helpful for quantifying phenolic compounds in S. glaucus was established.
\end{abstract}

\section{Introduction}

Medicinal plants have been widely explored for their various biological activities and due to their safety and efficacy [1]. Phenolic compounds are a type of phytocompounds that are ubiquitously found in several plant species. These compounds have been widely studied due to their enormous beneficial properties and biological activities [2]. Additionally, several plants rich in phenolic compounds have shown promising results for reducing or preventing various chronic diseases, including cancer and cardiovascular diseases [3]. Furthermore, the phenolic content in these plants allows them to have several beneficial properties, including antioxidant and anticancer properties [4]. Therefore, the potential antioxidant and anticancer properties from new plant species are being studied on a global scale.

The Senecio genus represents the largest genus of the Asteraceae family and includes more than 1500 species of herbs and trees [5]. Senecio species have traditionally been utilized in folk medication for various ailments, including treatment for cough, accelerating wound healing, and as treatments for asthma and eczema [6]. In addition, several classes of various natural compounds from the Senecio genera have been isolated and characterized [7-10]. Some of these classes of natural products have shown significant medicinal properties, such as antiviral [11], antioxidant [12], antifungal, antibacterial [13], antidiabetic [14], and cytotoxic properties [15-17]. 
Senecio glaucus is one of the most important species from the Senecio genus. It is an annual herbaceous plant. The presence of bioactive compounds in S. glaucus, such as phenolics, saponins, flavonoids, and tannins, as well as some volatile essential oils, has been reported [18]. S. glaucus reportedly exhibits significant cytotoxic activity against colon carcinoma cells [19]. As part of our systematic investigation of various plant species scattered in Saudi Arabia, we aimed to evaluate the in vitro antioxidant and cytotoxic effects of $S$. glaucus. In addition, we also aimed to quantitatively estimate the presence of total phenolics and some phenolic acids, such as gallic acid (GA) and vanillic acid (VA).

\section{Materials and Methods}

2.1. Plant Collection and Authentication. The aerial parts (leaves and stems) from S. glaucus were collected during the autumn season in 2018 from the southern region of Saudi Arabia. To ensure that the leaves and stems collected were S. glaucus, these were authenticated by an expert taxonomist in the herbarium of Pharmacognosy Department, College of Pharmacy, King Saud University, Riyadh, Saudi Arabia.

2.2. Crude Extracts and Fractions Preparation. The aerial parts of $S$. glaucus were dried in a ventilated room and crushed to a fine powder. The crude extract was prepared by soaking $500 \mathrm{~g}$ of the dry powder in $3 \mathrm{~L}$ of ethanol for $48 \mathrm{~h}$. A rotary evaporator was then used to concentrate the crude extract $(60 \mathrm{~g})$ which was then partitioned using different solvents, including $n$-hexane (Hex), chloroform $\left(\mathrm{CHCl}_{3}\right)$, and $n$-butanol (ButOH) producing $8 \mathrm{~g}, 13 \mathrm{~g}$, and $22 \mathrm{~g}$ of dried extracts, respectively.

2.3. Estimation of Total Phenol Content. The crude extract and fractions of S. glaucus were quantitatively examined for total phenolic content using the standard Folin-Ciocalteau spectrophotometric method [20]. For this procedure, $0.5 \mathrm{ml}$ of each sample was added to $0.1 \mathrm{ml}$ of Folin-Ciocalteau reagent $(0.5 \mathrm{~N})$ and mixed thoroughly. Subsequently, $2.5 \mathrm{ml}$ of sodium carbonate $\left(\mathrm{Na}_{2} \mathrm{CO}_{3}\right)$ was added, and the mixture was left to stand for $0.5 \mathrm{~h}$ after mixing. Optical density was measured at $760 \mathrm{~nm}$. Total phenolic contents were presented as milligram equivalents of GA (GAE)/g of the extract.

\subsection{Determination of Antioxidant Activity}

2.4.1. DPPH Radical Scavenging Activity. The crude extract and fractions of $S$. glaucus were screened for antioxidative activity using 2,2-diphenyl-1-picrylhydrazyl (DPPH) as described by Brand et al. [21]. In brief, $500 \mu \mathrm{L}$ of each sample at various concentrations from each fraction was mixed with $125 \mu \mathrm{L}$ DPPH solution $(1 \mathrm{mM})$ and $375 \mu \mathrm{L}$ methanol and further incubated for $30 \mathrm{~min}$. Finally, UV-spectrophotometer absorbance measurement at $\lambda=517 \mathrm{~nm}$ was applied to demonstrate the anti-DPPH activity using the following formula:

$$
\% \text { of antiradical activity }=\frac{\text { Abs of control }- \text { Abs of sample }}{\text { Abs of control } \times 100} \text {. }
$$

2.4.2. ABTS Radical Cation Scavenging Activity. The antioxidant capacity of $S$. glaucus crude extract and fractions was estimated utilizing the ABTS method as utilized by Li et al. [22], with slight modifications. In brief, ABTS (7 mM) and potassium persulfate $(2.45 \mathrm{mM})$ aqueous solutions were mixed, incubated for $0.5 \mathrm{~h}$, and kept in the refrigerator for $24 \mathrm{~h}$, after which it was diluted with ethanol. Thereafter, the ABTS solution $(50 \mu \mathrm{g} / \mathrm{ml})$ was mixed with different concentrations for each fraction $(1: 1)$. The antioxidant percentage activity of $S$. glaucus fractions was demonstrated based on the reduction of ABTS, which was optically measured at $734 \mathrm{~nm}$ using the following formula [23]:

$\%$ of radical scavenging activity $=\frac{\text { Abs control }- \text { Abs sample }}{\text { Abs control } \times 100 \text {. }}$

2.5. Cell Viability (MTT Assay). Cell viability MTT assay was carried out according to Alqahtani et al. [24]. In brief, A549 (lung), MCF-7 (breast), and HepG2 (liver) cancer cells were harvested, counted, and plated on the bottom of a 24 -well plate $\left(5 \times 10^{4}\right.$ cells/well) for $24 \mathrm{~h}$ to allow for attachment. Various concentrations of $S$. glaucus fractions were added to each well and incubated with the cells at $37^{\circ} \mathrm{C}$ in the presence of $5 \% \mathrm{CO}_{2}$. After $48 \mathrm{~h}, 0.1 \mathrm{ml}$ of $5 \mathrm{mg} / \mathrm{ml} \mathrm{MTT}$ was added to each well, and the plates were again incubated at $37^{\circ} \mathrm{C}$ and $5 \% \mathrm{CO}_{2}$ for 2-4 hours. Next, the media were aspirated, a solution of $0.01 \mathrm{~N} \mathrm{HCl}$ in isopropanol was added to each well, and the plates were placed in a shaker for $10 \mathrm{~min}$ to dissolve the formed formazan crystals. The absorbance was read at $570 \mathrm{~nm}$ using a microplate reader. The concentration at which cell viability is reduced by $50 \%\left(\mathrm{IC}_{50}\right)$ was calculated using OriginPro 8.5 software.

2.6. HPLC Analysis. HPLC-grade acetonitrile and acetic acid were obtained from VWR International Ltd. (Poole, England). The water used in the analysis was purified by a MilliQ purification system manufactured by Purelab Flex: Elga Veolia Ltd. (High Wycombe, UK). Standard compounds of gallic acid ( $\geq 96 \%)$ and vanillic acid (99\%) were purchased from Sigma Aldrich (St. Louis, MO, USA). All solvents used during the mobile phase were previously filtered through $0.45 \mu \mathrm{m}$ Millipore and degassed prior to use. The standard solutions were prepared by dissolving the accurate weights of the reference standards in methanol to a concentration of $0.5 \mathrm{mg} / \mathrm{mL}$ and then further diluted with additional methanol to arrive at different diluted solutions for the preparation of standard calibration curves. All samples for HPLC analysis were filtered through $0.45 \mu \mathrm{m}$ Millipore and immediately used for analysis. 
2.6.1. Apparatus and Operating Parameters. The analysis was carried out by Shimadzu chromatographic system (Shimadzu, Kyoto, Japan) equipped with binary solvent delivery units (LC-10AD Prominence liquid chromatography pumps), Prominence UV/Vis detector (SPD-20A), and a system controller (CBM-20A Prominence Communication Bus Module) with LC solution software. Chromatographic analyses were performed on Shim-pack VP-ODS C18 reversed-phase column $(250 \times 4.6 \mathrm{~mm}, 5 \mu \mathrm{m}$, Shimadzu, Kyoto, Japan). The mobile phase was acetonitrile-wateracetic acid $(20: 80: 1)$ and increasing up to acetonitrile-water-acetic acid $(80: 20: 1)$ in 30 minutes. Chromatographic operations were carried out at a constant flow rate $(1 \mathrm{ml} / \mathrm{min})$ and ambient temperature. Detection was performed at $277 \mathrm{~nm}$ according to the ultraviolet (UV) absorption maxima of the two analytes.

2.7. Statistical Analysis. Each assay was done in triplicate for each fraction. The data presents the mean \pm SD from three independent experiments.

\section{Results}

3.1. Phenolic Contents of S. glaucus. The total phenolic contents from crude and fractions of S. glaucus are presented in Figure 1. The results show that the chloroform fraction had the highest concentration of phenolic contents (125.3 mg.GA/g). The remaining fractions also showed varied contents in terms of $\mathrm{mg} \cdot \mathrm{GA} / \mathrm{g}$ of dry extract (Figure 1).

3.2. Antioxidant Activity. The radical scavenging activity of S. glaucus fractions is shown in Table 1. In the ABTS test, S. glaucus displayed a remarkable capacity to scavenge free radicals at various concentrations. It was found that SGCF had the highest antioxidant content at a concentration of $1000 \mu \mathrm{g} / \mathrm{mL}$ with a value of 76.7 and $74.1 \%$ in $\mathrm{DPPH}$ and ABTS, respectively. In addition, the remaining fractions also showed variable antioxidant activities in both tests (Table 1).

3.3. Cytotoxicity of Different Cancer Cell Lines. All fractions showed cytotoxic activity in a dose-dependent manner (Figure 2). The most effective fractions were the chloroform fractions $\left(\mathrm{IC}_{50}=41.8\right)$, which showed potent cytotoxic activity against MCF-7, followed by the hexane fraction, which showed moderate cytotoxicity in comparison with the remaining fractions. The results of the cytotoxicity evaluation in terms of $\mathrm{IC}_{50}$ against all tested cell lines are summarized in Table 2.

3.4. HPLC Analysis. The wavelength maxima ( $\lambda \max$ ) of standard GA and VA were analyzed in order to obtain the optimal detection wavelength to be used for chromatographic analysis. The UV/vis spectrum scan of each HPLC peak was determined, and the detection wavelength was set according to the ultraviolet (UV) absorption maxima of the two analytes (Figure 3). Different mobile phase compositions, flow rates, and injection volumes were tested to improve the peak shape and resolution for the optimization of chromatographic conditions. Recognition and peak assignment of GA and VA were identified by comparing the mean of retention times and absorption spectrum of individual standards with the chromatographic profile of the extract (Figure 4). Once the optimum chromatographic conditions that allowed the satisfactory resolution of the two studied analytes were detected, the performance of the HPLC method was assessed by validating the method with an S. glaucus sample. The quality parameters of the chromatographic method, such as linearity, sensitivity, precision, and accuracy, were determined $[25,26]$.

\subsection{Calibration Curves, Linearity, and Sensitivities (Detection} Limits). Detector response linearity was evaluated based on calibration curves. Calibration curves were studied based on the linear correlation between the peak area ( $y$-axis) and concentration $(\mu \mathrm{g} / \mathrm{mL})$ of the standard ( $x$-axis). Linear curves for each analyte were constructed using six concentration points, in triplicate, for each phenolic compound. The correlation coefficient, intercept, and the slope of each calibration line were calculated using regression analysis. The linear range was found to be from 0.10 to $20.00 \mu \mathrm{g} / \mathrm{mL}$ for GA and from 0.20 to $20.00 \mu \mathrm{g} / \mathrm{mL}$ for VA. The values of the limit of detection (LOD) of the proposed method were 0.16 and $0.12 \mu \mathrm{g} / \mathrm{mL}$ for GA and VA, respectively (Table 3), and those for the corresponding limit of quantification (LOQ) were 0.47 and $0.36 \mu \mathrm{g} / \mathrm{mL}$. The linear curves showed best-fit linear regression (coefficient of determination $\mathrm{r}^{2}>0.997$ for GA and VA, Table 3).

3.6. Precision and Accuracy. The quantification, repeatability (intraday), and intermediate precision (interday) of the method proposed here were measured and presented as the relative standard deviation (\% RSD). The experimental data are shown in Table 4 . The proposed method was precise, as indicated by \% RSD values for the intraday (within 1 day) and interday (between three consecutive days) precision measurements. The precision assays for GA and VA were in accordance with the limit recommended by the International Conference on Harmonization (ICH) guidelines [27] as the \% RSD values ranged from 1.13-3.45 to $1.53-4.10 \%$ for intra- and interassay precision values, respectively (Table 5 ).

Accuracy was determined through percent recovery with the addition of the standard solution to the S. glaucus sample at three different concentrations: $0.50 \mu \mathrm{g} / \mathrm{mL}, 5.00 \mu \mathrm{g} / \mathrm{mL}$, and $20.00 \mu \mathrm{g} / \mathrm{mL}$. Table 5 shows the mean recoveries calculated on the basis of determination after exposing the samples with known amounts of analytes at three concentration levels. The mean recovery values of the two investigated analytes ranged from 95.43 to $100.39 \%$, and their $\%$ RSD at each concentration was all less than $1.60 \%$, which indicated that the proposed method was accurate enough for the quantification of VA and GA in S. glaucus. 
TABLE 1: DPPH and ABTS scavenging activity of S. glaucus extract and fractions.

\begin{tabular}{|c|c|c|c|c|c|}
\hline \multirow{2}{*}{ Sample } & \multicolumn{5}{|c|}{ (DPPH radical scavenging activity in \%) } \\
\hline & 10 & 50 & 100 & 500 & 1000 \\
\hline SG-crude & $2.4 \pm 3.4$ & $10.4 \pm 4.3$ & $21.6 \pm 3.6$ & $35.9 \pm 3.5$ & $54.4 \pm 2.7$ \\
\hline SG-hex & $2.3 \pm 0.3$ & $10.2 \pm 3.1$ & $19.7 \pm 0.7$ & $31.7 \pm 2.1$ & $44.7 \pm 1.3$ \\
\hline $\mathrm{SG}-\mathrm{CHCl}_{3}$ & $12.7 \pm 4.1$ & $20.3 \pm 4.3$ & $43.3 \pm 3.9$ & $61.3 \pm 4.1$ & $76.7 \pm 3.2$ \\
\hline SG-ButOH & $11.2 \pm 3.6$ & $19.1 \pm 4.4$ & $31.5 \pm 3.4$ & $47.5 \pm 2$ & $63.6 \pm 2.3$ \\
\hline \multirow[t]{2}{*}{ Ascorbic acid } & $80.7 \pm 2.5$ & $85.1 \pm 1.3$ & $85 \pm 3.2$ & $88.7 \pm 2.4$ & $90.7 \pm 4.4$ \\
\hline & \multicolumn{5}{|c|}{ (ABTS radical cation scavenging activity in \%) } \\
\hline SG-crude & $6.21 \pm 4.2$ & $12.2 \pm 3.1$ & $22.3 \pm 2.4$ & $38.3 \pm 4.6$ & $51.6 \pm 3.7$ \\
\hline SG-hex & $2.3 \pm 3.1$ & $5.4 \pm 3.1$ & $12.6 \pm 2.7$ & $20.6 \pm 3.1$ & $41.7 \pm 3.1$ \\
\hline $\mathrm{SG}-\mathrm{CHCl}_{3}$ & $13.2 \pm 3.3$ & $19.3 \pm 2.7$ & $34.3 \pm 3.2$ & $56.3 \pm 3.5$ & $74.1 \pm 2.3$ \\
\hline SG-ButOH & $6.21 \pm 4.2$ & $19.2 \pm 3.1$ & $32.3 \pm 2.4$ & $48.3 \pm 4.6$ & $61.6 \pm 3.7$ \\
\hline Ascorbic acid & $80.7 \pm 2.4$ & $81.2 \pm 2.1$ & $84.2 \pm 3.2$ & $87.2 \pm 2.4$ & $88.7 \pm 2.6$ \\
\hline
\end{tabular}

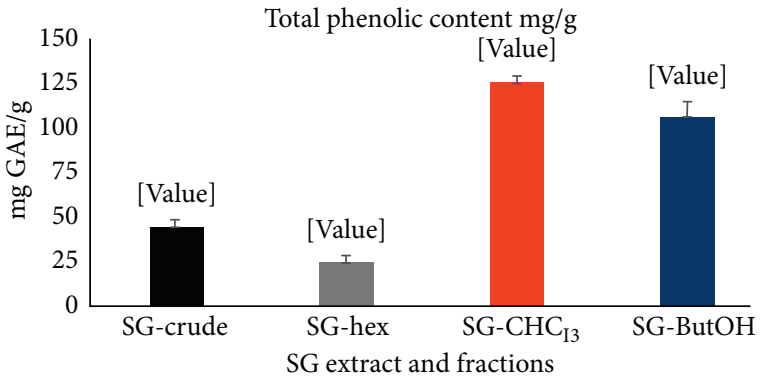

Figure 1: S. glaucus total phenolic content.

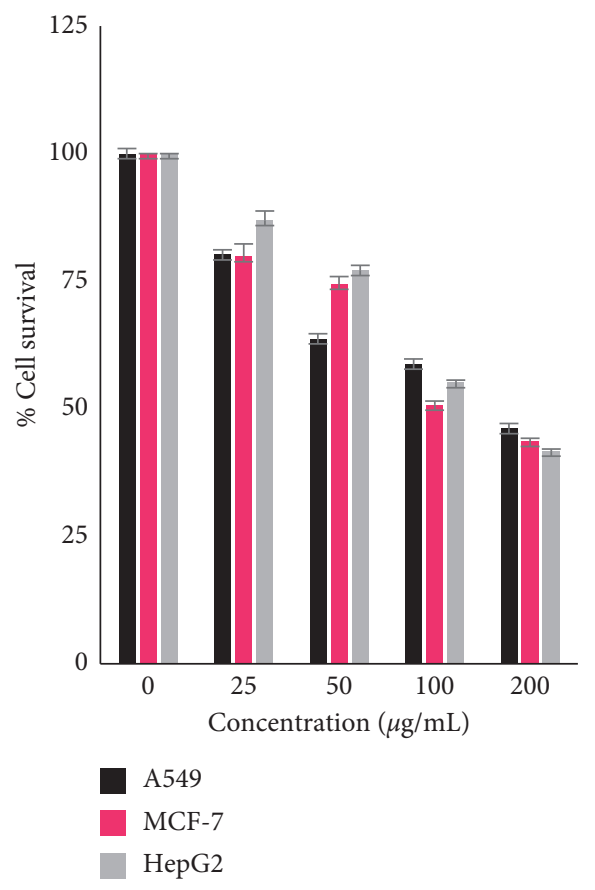

(a)

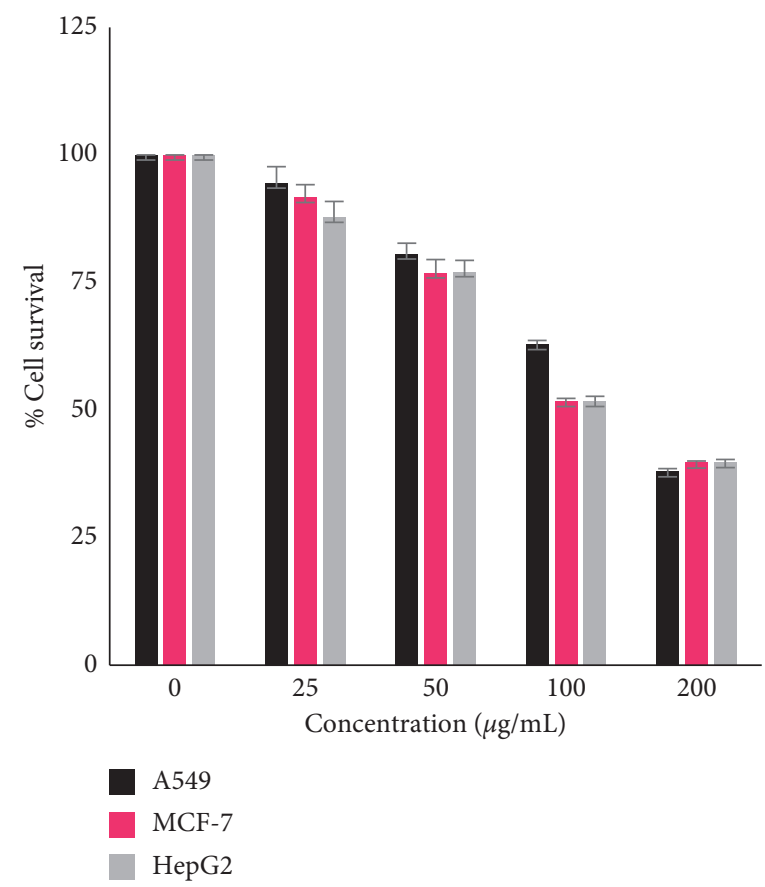

(b)

Figure 2: Continued. 


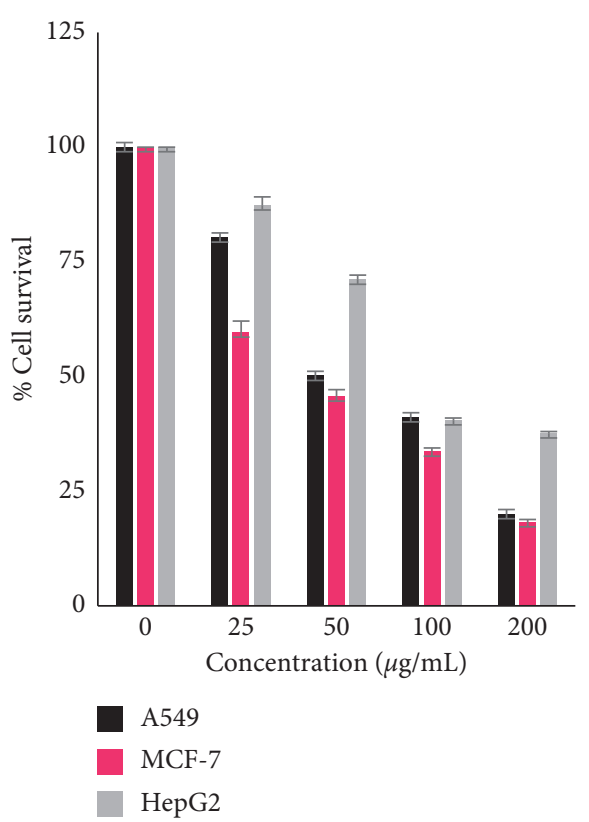

(c)

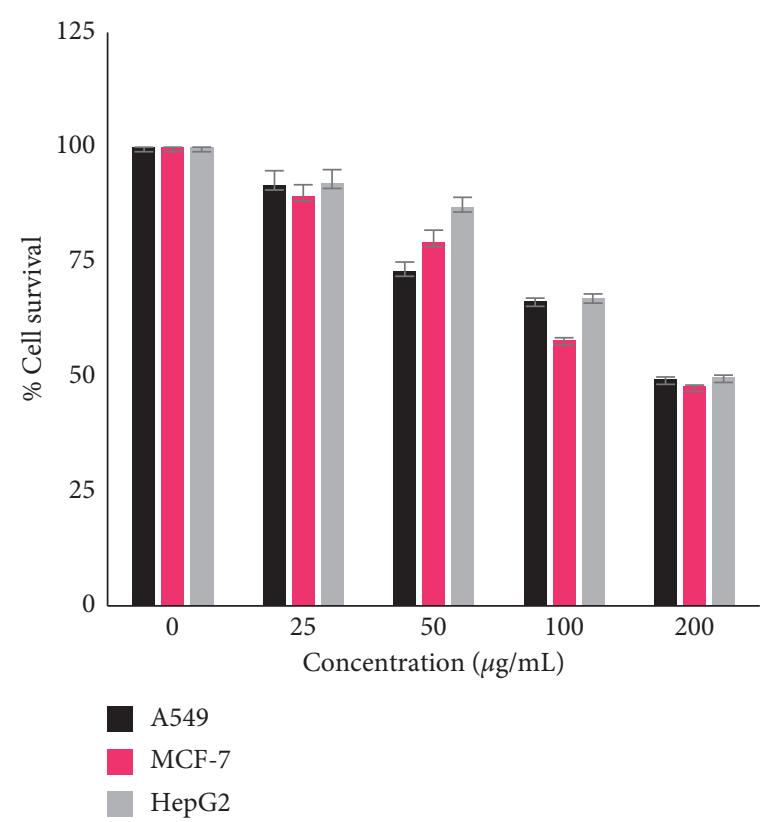

(d)

FIgURE 2: Inhibition of cellular viability of cancer cell lines by S. glaucus fractions. The cells were treated for $48 \mathrm{~h}$ and cytotoxicity of S. glaucus fractions was estimated using the MTT assay. Data represents the mean of three independent experiments, with each carried out in triplicate. (a) SG-crude. (b) SG-hex. (c) SG-CHCL . (d) SG-BuOH.

TABLE 2: The $\mathrm{IC}_{50}$ values of $S$. glaucus fractions in different cancer cells.

\begin{tabular}{lccc}
\hline \multirow{2}{*}{ Fraction } & \multicolumn{3}{c}{ IC $_{50}$ values \pm SD $(\mu \mathrm{g} / \mathrm{mL})$} \\
& MCF-7 & HepG2 & A549 \\
\hline Crude & $101.3 \pm 1.7$ & $137.3 \pm 1.1$ & $170.1 \pm 1.8$ \\
$n$-Hex & $114 \pm 1.5$ & $112.3 \pm 1.8$ & $151.3 \pm 1.6$ \\
CHCL $_{3}$ & $41.8 \pm 0.8$ & $84.2 \pm 1.2$ & $49.8 \pm 1.1$ \\
$n$-Butanol & $178.6 \pm 1.6$ & $199 \pm 1$ & $196 \pm 1.2$ \\
Doxorubicin & $0.8 \pm 0.2$ & $1 \pm 0.3$ & $0.9 \pm 0.4$ \\
\hline
\end{tabular}

\section{Discussion}

Plants are a valuable source of different phytochemicals that display various biological activities, including antioxidant and anticancer properties. The exploration of natural sources in search of biological agents with fewer side effects and good efficacy compared to synthesized compounds is continuously being conducted. In this report, we documented the profile of phenolic contents and the antioxidant and cytotoxic properties of S. glaucus found in Saudi Arabia. Species of the Senecio genus are known for containing an abundance of phenolic compounds [28-30]. Albayrak et al. (2014) reported that several species of the Senecio genus growing in Turkey contained high total phenolic contents that ranged from $11.63 \pm 2.1 \mathrm{mg} \mathrm{GAE} / \mathrm{g}$ extract in S. viscosus to $117.45 \pm 1.8 \mathrm{mg} \mathrm{GAE} / \mathrm{g}$ in S. cilicius [30]. The total phenolic contents for the same species found in Egypt also showed comparable values [19].

Interest in natural antioxidants from medicinal plants has increased due to the safety of these antioxidants in comparison with synthetic compounds [31]. These natural antioxidants, especially phenolic compounds, have a fundamental role in reducing the harmful effects of free radicals [32]. This correlation between phenolic compounds and scavenging activity was clearly reported in several studies [33-35]. The antioxidative potency of plants can be evaluated through their ability to scavenge free radicals. The DPPH and ABTS methods are the most widely utilized assays for determining free radical scavenging activity $[36,37]$. In this study, we showed that $S$. glaucus displayed strong antioxidant activity through two screening methods. The results were compared with a recent study which reported that essential oils from S. glaucus exerted a concentration-dependent DPPH scavenging activity [38]. Furthermore, Mohamed (2015) found that root methyl alcohol extract of $S$. glaucus growing in Egypt had an antioxidant activity with $\mathrm{IC}_{50}=79.57 \pm 0.74 \mu \mathrm{g} / \mathrm{ml}$ using the DPPH method [19]. There were no major differences between our results and the results of other previously reported studies, and this may be due to the presence of the same chemical constituents, including GA and VA. Moreover, the presence of GA and VA, which have known antioxidant properties [27,39], verified the reported antioxidant activity of S. glaucus. Furthermore, a hybrid of GA and another phenolic antioxidant strongly enhanced the plant's antioxidant potential [40].

Our results show that $S$. glaucus extracts had promising cytotoxic activity. We found that $S$. glaucus extracts decreased the viability of various cancer cells. Data from the literature on the cytotoxicity of S. glaucus are still scarce. A new study by Ramadan et al. (2020) showed that S. glaucus essential oils exerted cytotoxic activity against breast cancer cells [38]. Phenolic compounds, including GA and VA, are 


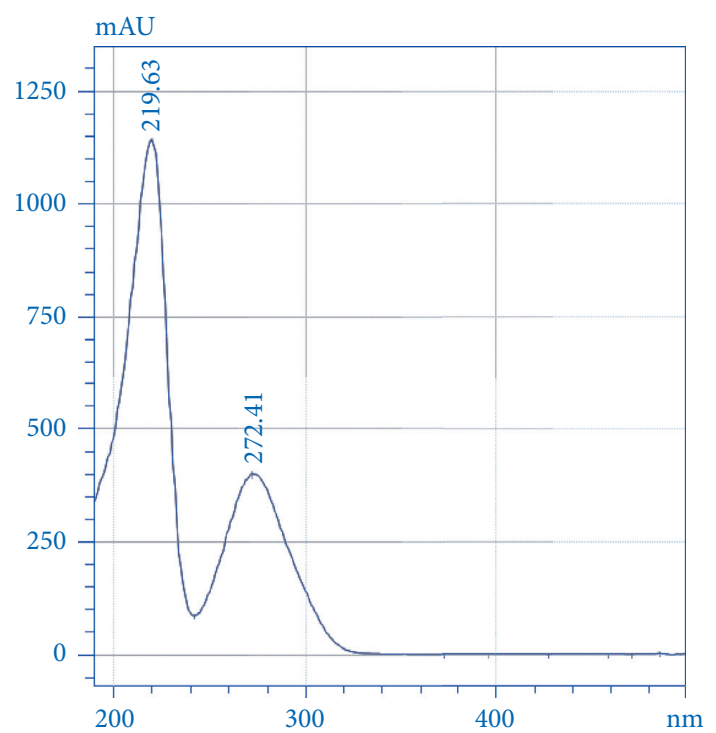

(a)

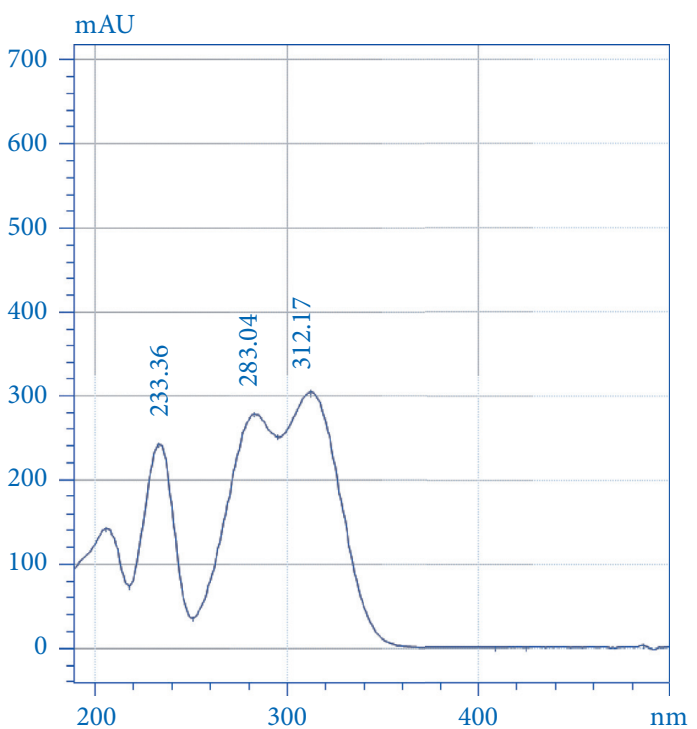

(b)

Figure 3: UV/vis spectrum scan of GA at a retention time of $10.89 \mathrm{~min}$ (a) and VA at a retention time of $14.45 \mathrm{~min}$ (b).

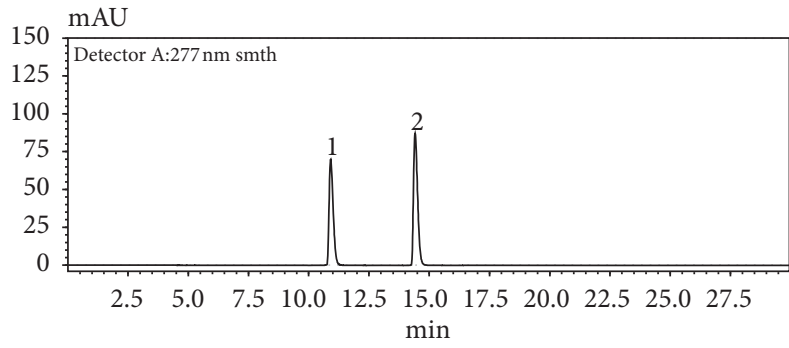

(a)

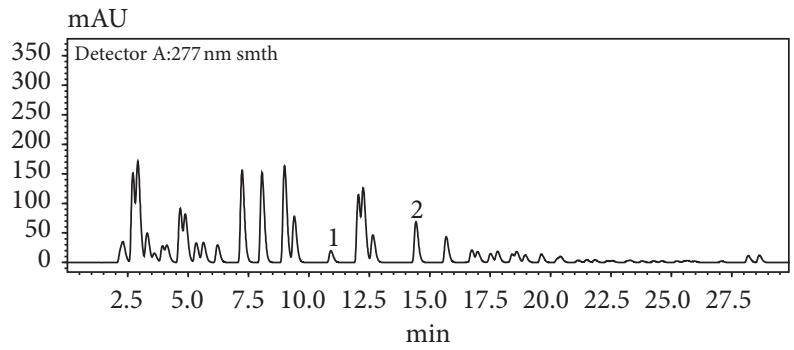

(b)

FIgUre 4: HPLC chromatograms of (a) standard phenolic acids and (b) extract. Peaks: (1) GA and (2) VA.

TABLE 3: Linear regression parameters and sensitivity data for two phenolic acids using the proposed HPLC method.

\begin{tabular}{lccccc}
\hline Analyte & Retention time $(\mathrm{min})$ & Range $(\mu \mathrm{g} / \mathrm{mL})$ & Linearity $\left(\mathrm{r}^{2}\right)$ & LOD $(\mu \mathrm{g} / \mathrm{mL})$ & 0.16 \\
\hline GA & $10.90 \pm 0.03$ & $0.10-20.00$ & 0.9976 & 0.47 \\
VA & $14.42 \pm 0.04$ & $0.20-20.00$ & 0.9989 & 0.12 & 0.36 \\
\hline
\end{tabular}

TABLE 4: Analytical results of accuracy, intraday, and interday precision.

\begin{tabular}{|c|c|c|c|c|c|}
\hline \multirow{2}{*}{ Analyte } & \multirow{2}{*}{ Con. $(\mu \mathrm{g} / \mathrm{mL})$} & \multicolumn{2}{|c|}{ Intraday $(n=3)$} & \multicolumn{2}{|c|}{ Interday $(n=3)$} \\
\hline & & RSD (\%) & Accuracy (\%) & RSD (\%) & Accuracy (\%) \\
\hline \multirow{3}{*}{ GA } & 0.5 & 1.94 & 99.57 & 3.44 & 97.54 \\
\hline & 5 & 3.45 & 98.68 & 4.10 & 98.27 \\
\hline & 20 & 2.61 & 97.77 & 1.53 & 98.26 \\
\hline \multirow{3}{*}{ VA } & 0.5 & 1.18 & 100.69 & 2.12 & 96.30 \\
\hline & 5 & 2.87 & 98.10 & 2.32 & 98.71 \\
\hline & 20 & 1.13 & 97.63 & 3.10 & 99.73 \\
\hline
\end{tabular}


TABLE 5: Results of analytical recovery $(n=6)$.

\begin{tabular}{lccc}
\hline Analyte & Added $(\mu \mathrm{g} / \mathrm{mL})$ & Recovery $(\%)(\mathrm{mean} \pm \mathrm{SD})$ & RSD $(\%)$ \\
\hline & 0.5 & $98.02 \pm 1.57$ & 1.60 \\
GA & 5 & $99.01 \pm 0.88$ & 0.88 \\
& 20 & $95.43 \pm 1.02$ & 1.07 \\
VA & 0.5 & $97.93 \pm 1.24$ & 1.27 \\
& 5 & $96.07 \pm 0.67$ & 0.70 \\
\hline
\end{tabular}

among the best candidates for mediating anticancer activities [7, 27, 39, 41]. It is apparent that phenolic contents determined by colorimetric standard methods do not give the exact quantity of the phenolic compounds found in plant extracts. Therefore, chromatographic methods, such as HPLC, play an important role in the isolation and quantification of phenolic compounds [42, 43]. Our study showed that GA and VA were abundant compounds in SGCF (Figure 3). These results are in agreement with Mohamed (2015), who detected the presence of GA, VA, and several other phenolic compounds from the roots of S. glaucus found in Egypt. Overall, these results demonstrate that the antioxidant and cytotoxic activities of S. glaucus were likely due to the combination of phenolic acids found in these species.

\section{Conclusion}

The present study determined the total phenolic contents of S. glaucus found in Saudi Arabia. In accordance with a recent study, our data indicate that $S$. glaucus are a good potential source of natural antioxidants, such as GA and VA. The chloroform fraction of $S$. glaucus (SGCF) exhibited the highest antioxidant and cytotoxic activities, which was positively correlated with their phenolic profile. The HPLC method we developed was approved and used to determine the GA and VA content in S. glaucus. It can be concluded that the combination of these two bioactive compounds in S. glaucus is crucial for the plants' antioxidant and cytotoxic activities which confirm their beneficial effect on human health. Thus, the findings of this study encourage further research in order to fully elucidate the bioactive constituents of S. glaucus, which may lead to the discovery of novel and effective drugs against degenerative diseases.

\section{Data Availability}

The data sets used and/or analyzed during the current study are available from the corresponding author upon reasonable request.

\section{Conflicts of Interest}

The authors declare that there are no conflicts of interest.

\section{Acknowledgments}

The authors extend their appreciation to the Deanship of Scientific Research at King Saud University for funding this work through research group RG-1441-486. In addition, the authors thank the Deanship of Scientific Research and RSSU at King Saud University for their technical support.

\section{References}

[1] M. Aye, H. Aung, M. Sein, and C. Armijos, "A review on the phytochemistry, medicinal properties and pharmacological activities of 15 selected Myanmar medicinal plants," Molecules, vol. 24, no. 2, p. 293, 2019.

[2] I. O. Minatel, C. V. Borges, M. I. Ferreira et al., "Phenolic compounds: functional properties, impact of processing and bioavailability," Phenolic Compounds Biological Activitypp. 1-24, InTech, Rijeka, Croatia, 1 edition, 2017.

[3] M. Sharifi-Rad, N. V. Anil Kumar, P. Zucca et al., "Lifestyle, oxidative stress, and antioxidants: back and forth in the pathophysiology of chronic diseases," Frontiers in Physiology, vol. 11, p. 694, 2020.

[4] H. Zaid, M. Silbermann, A. Amash, D. Gincel, E. Abdel-Sattar, and N. B. Sarikahya, "Medicinal plants and natural active compounds for cancer chemoprevention/chemotherapy," Evidence-Based Complementary and Alternative, vol. 2017, p. 2, Article ID 7952417, 2017.

[5] I. Faraone, D. Rai, L. Chiummiento et al., "Antioxidant activity and phytochemical characterization of Senecio clivicolus wedd," Molecules, vol. 23, no. 10, p. 2497, 2018.

[6] L. Oladipupo and O. Adebola, "Chemical composition of the essential oils of the flowers, leaves and stems of two senecio polyanthemoides Sch. Bip. samples from South Africa," Molecules, vol. 14, no. 6, pp. 2077-2086, 2009.

[7] S.-M. Huang, C.-L. Hsu, H.-C. Chuang, P.-H. Shih, C.-H. Wu, and G.-C. Yen, "Inhibitory effect of vanillic acid on methylglyoxal-mediated glycation in apoptotic Neuro-2A cells," Neurotoxicology, vol. 29, no. 6, pp. 1016-1022, 2008.

[8] E. M. Suleimen, Z. B. Iskakova, Z. A. Ibataev, P. G. Gorovoi, R. V. Dudkin, and S. A. Ross, "Constituent composition and cytotoxic activity of essential oil from Senecio argunensis," Chemistry of Natural Compounds, vol. 52, no. 6, pp. 1125-1126, 2016.

[9] S.-M. Bai, H.-M. Ren, G.-J. Zheng, and G. Chen, "Senobtusin, a novel alkaloid with amidine moiety from Senecio obtusatus wall. ex DC," Natural Product Research, vol. 31, no. 20, pp. 2450-2453, 2017.

[10] A. M. Zaher, R. Sultan, T. Ramadan, and A. Amro, "New antimicrobial and cytotoxic benzofuran glucoside from Senecio glaucus L," Natural Product Research, pp. 1-6, 2020. 
[11] B. N. Dhawan, "Anti-viral activity of Indian plants," Proceedings of the National Academy of Sciences, India Section B: Biological Sciences, vol. 82, no. 1, pp. 209-224, 2012.

[12] R. Tundis, F. Menichini, M. R. Loizzo, M. Bonesi, U. Solimene, and F. Menichini, "Studies on the potential antioxidant properties of Senecio stabianusLacaita (Asteraceae) and its inhibitory activity against carbohydrate-hydrolysing enzymes," Natural Product Research, vol. 26, no. 5, pp. 393-404, 2012.

[13] M. R. Loizzo, G. A. Statti, R. Tundis et al., "Antibacterial and antifungal activity of Senecio inaequidens DC. and Senecio vulgaris L," Phytotherapy Research, vol. 18, no. 9, pp. 777-779, 2004.

[14] I. Okoro, I. Umar, S. Atawodi, and K. Anigo, "Antidiabetic effect of Cleome rutidosperma DC and Senecio biafrae (Oliv. \& Hiern) extracts in streptozotocin-induced diabetic rats," International Journal of Pharmaceutical Sciences and Research, vol. 5, no. 6, pp. 2480-2497, 2014.

[15] V. Steenkamp, M. J. Stewart, S. Van der Merwe, M. Zuckerman, and N. J. Crowther, "The effect of Senecio latifolius a plant used as a South African traditional medicine, on a human hepatoma cell line," Journal of Ethnopharmacology, vol. 78, no. 1, pp. 51-58, 2001.

[16] P. Barbetti, G. Fardella, I. Chiappini, A. Menghini, and V. Scarcia, "In vitro cytostatic activity of chromatographic fractions of extracts from some species of compositae," Arzneimittel-forschung, vol. 36, no. 3, pp. 425-427, 1986.

[17] V. Christov, B. Mikhova, R. Alexandrova, D. Dimitrova, E. Nikolova, and L. Evstatieva, "Alkaloids from the roots of Senecio macedonicus Griseb," Zeitschrift für Naturforschung C, vol. 57, no. 9-10, pp. 780-784, 2002.

[18] Y. El-Amier, A. Abdelghany, and A. Abed Zaid, "Green synthesis and antimicrobial activity of Senecio glaucus-Mediated silver nanoparticles," Research Journal of Pharmaceutical, Biological and Chemical Sciences, vol. 5, no. 5, pp. 631-642, 2014.

[19] S. Mohamed, "Phytochemical and biological study of (Senecio glaucus subsp. coronopifolius) (Maire) c. alexander growing in Egypt," Al-Azhar Journal of Pharmaceutical Sciences, vol. 52, no. 2, pp. 283-298, 2015.

[20] R. M. Lamuela-Raventós, "Folin-Ciocalteu method for the measurement of total phenolic content and antioxidant capacity," Measurement of Antioxidant Activity \& Capacity Recent Trends and Applications, pp. 107-117, John Wiley \& Sons, Hoboken, USA, 2018.

[21] W. Brand-Williams, M. E. Cuvelier, and C. Berset, "Use of a free radical method to evaluate antioxidant activity," LWT-Food Science and Technology, vol. 28, no. 1, pp. 25-30, 1995.

[22] W. Li, F. S. Hosseinian, A. Tsopmo, J. K. Friel, and T. Beta, "Evaluation of antioxidant capacity and aroma quality of breast milk," Nutrition, vol. 25, no. 1, pp. 105-114, 2009.

[23] X. Li, X. Wang, D. Chen, and S. Chen, "Antioxidant activity and mechanism of protocatechuic acid in vitro," Functional Foods in Health and Disease, vol. 1, no. 7, pp. 232-244, 2011.

[24] A. S. Alqahtani, F. A. Nasr, O. M. Noman et al., "Cytotoxic evaluation and anti-angiogenic effects of two furano-sesquiterpenoids from commiphora myrrh resin," Molecules, vol. 25, no. 6, p. 1318, 2020.

[25] ICH Guideline, Q2 R1Validation of Analytical Procedures: Text and Methodology, vol. 1, pp. 1-15, ICH, Geneva, Switzerland, 2005.

[26] M. N. Irakli, V. F. Samanidou, C. G. Biliaderis, and I. N. Papadoyannis, "Simultaneous determination of phenolic acids and flavonoids in rice using solid-phase extraction and RP-HPLC with photodiode array detection," Journal of Separation Science, vol. 35, no. 13, pp. 1603-1611, 2012.

[27] G. Velderrain-Rodríguez, H. Torres-Moreno, M. VillegasOchoa et al., "Gallic acid content and an antioxidant mechanism are responsible for the antiproliferative activity of 'ataulfo' mango peel on LS180 cells," Molecules, vol. 23, no. 3, p. $695,2018$.

[28] D.-p. Tan, G.-x. Chou, and Z.-t. Wang, "Phenolic compounds from Senecio scandens," Biochemical Systematics and Ecology, vol. 38, no. 1, pp. 122-124, 2010.

[29] B. M. Mandić, D. M. Gođevac, L. V. Vujisić et al., "Semiquinol and phenol compounds from seven Senecio species," Chemical Papers-Slovak Academy of Sciences, vol. 65, no. 1, pp. 90-92, 2011.

[30] S. Albayrak, A. Aksoy, L. Yurtseven, and A. Yaşar, "A comparative study on phenolic components and biological activity of some Seneciospecies in Turkey," Journal of Pharmacy and Pharmacology, vol. 66, no. 11, pp. 1631-1640, 2014.

[31] S. C. Lourenço, M. Moldão-Martins, and V. D. Alves, “Antioxidants of natural plant origins: from sources to food industry applications," Molecules, vol. 24, no. 22, p. 4132, 2019.

[32] D.-P. Xu, Y. Li, X. Meng et al., "Natural antioxidants in foods and medicinal plants: extraction, assessment and resources," International Journal of Molecular Sciences, vol. 18, no. 1, p. 96, 2017.

[33] H. Wang, D. Gan, X. Zhang, and Y. Pan, “Antioxidant capacity of the extracts from pulp of Osmanthus fragrans and its components," LWT-Food Science and Technology, vol. 43, no. 2 , pp. $319-325,2010$.

[34] S. Mathew, T. E. Abraham, and Z. A. Zakaria, "Reactivity of phenolic compounds towards free radicals under in vitro conditions," Journal of Food Science and Technology, vol. 52, no. 9, pp. 5790-5798, 2015.

[35] B. M. Moukette, C. A. Pieme, J. R. Njimou, C. P. Biapa, B. Marco, and J. Y. Ngogang, "In vitro antioxidant properties, free radicals scavenging activities of extracts and polyphenol composition of a non-timber forest product used as spice: monodora myristica," Biological Research, vol. 48, no. 1, p. 15, 2015.

[36] M. N. Alam, N. J. Bristi, and M. Rafiquzzaman, "Review on in vivo and in vitro methods evaluation of antioxidant activity," Saudi Pharmaceutical Journal, vol. 21, no. 2, pp. 143-152, 2013.

[37] A. M. Pisoschi, A. Pop, C. Cimpeanu, and G. Predoi, “Antioxidant capacity determination in plants and plant-derived products: a review," Oxidative Medicine and Cellular Longevity, vol. 2016, Article ID 9130976, 36 pages, 2016.

[38] T. Ramadan, A. Zaher, A. Amro, and R. Sultan, "Chemical composition and biological activity of capetula and shoots essential oils of Senecio glaucus L," Journal of Essential Oil Bearing Plants, vol. 23, no. 1, pp. 168-183, 2020.

[39] K. Vinothiya and N. Ashokkumar, "Modulatory effect of vanillic acid on antioxidant status in high fat diet-induced changes in diabetic hypertensive rats," Biomedicine \& Pharmacotherapy, vol. 87, pp. 640-652, 2017.

[40] B. Badhani, N. Sharma, and R. Kakkar, "Gallic acid: a versatile antioxidant with promising therapeutic and industrial applications," Rsc Advances, vol. 5, no. 35, pp. 27540-27557, 2015.

[41] B. R. You, H. J. Moon, Y. H. Han, and W. H. Park, "Gallic acid inhibits the growth of HeLa cervical cancer cells via apoptosis and/or necrosis," Food and Chemical Toxicology, vol. 48, no. 5, pp. 1334-1340, 2010. 
[42] A. Ghasemzadeh and H. Z. E. Jaafar, "Profiling of phenolic compounds and their antioxidant and anticancer activities in pandan (Pandanus amaryllifolius Roxb.) extracts from different locations of Malaysia," BMC Complementary and Alternative Medicine, vol. 13341 pages, 2013.

[43] C. F. Van Sumere, "2-phenols and phenolic acids," in Methods in Plant Biochemistry, J. B. Harborne, Ed., pp. 29-73, Academic Press, Cambridge, USA, 1989. 